\title{
Effect of Water Immersion on Monomer and Strength of FRC
}

\author{
W. SISWOMIHARDJO*, S. SUNARINTYAS*, A.F. OMAR KHATAB KHAN*, N.S.I. \\ SAHIDU*, J.P. MATINLINNA** \\ * Faculty of Dentistry, Universitas Gadjah Mada, Indonesia \\ **Faculty of Dentistry, University of Hong Kong, Hong Kong
}

\begin{abstract}
Purpose: There is an interest in the use of fiber-reinforced composite (FRC) to support the concept of minimal invasive dentistry. The exposure of FRC to the oral environment causes detrimental effect of water sorption. With time water molecules will act as plasticizers and decrease the mechanical properties. Monomer system is the backbone of the dental composite and residual monomer may dissolve in water. Some released monomer are known to ellicit cytotoxic effets, and methyl methacrylate (MMA) is mentioned as cytotoxic. This study investigated the effect of water immersion duration on monomer release and the compressive strength of fiber-reinforced composite.
\end{abstract}

Materials and Methods : Materials used were: E-glass fibre (Stick Tech, Finland), bis-GMA (Sigma-Aldrich, USA), MMA (ProSciTech, Australia), CQ (Esstech, USA) and CEMA (Esstech, USA). Fifteen specimens $(2 \mathrm{~mm} \times 2 \mathrm{~mm} \times 25 \mathrm{~mm})$ with the composition of: 78.4\% bis-GMA+19.6\%MMA+1.0\%CQ+1.0\%CEMA were prepared and divided into 2 groups: compressive strength (12 specimens) and residual monomer (3 specimens). Each specimen had two fiber rovings of $25 \mathrm{~mm}$ and placed in a mould, and light-cured with halogen light-curing unit on both sides for $3 \times 40$ s. Specimens from each group were divided into three groups based on the water immersion durations (1,14 and 21days) and immersed into $10 \mathrm{ml}$ distilled water of $37^{\circ} \mathrm{C}$. The three residual monomer test specimens were analyzed using HPLC to test the concentration. All compressive strength test specimens were tested using UTM (Torsee's UTM, Tokyo Testing Machine Mfg.,Co., Ltd.Japan) for the strength.

Results: The data of MMA concentration was descriptively analyzed. It started on day1 $(2352.96 \mu \mathrm{g} / \mathrm{ml})$ followed by an increase on day14 $(3567.15 \mu \mathrm{g} / \mathrm{ml})$ and decreased on day21 $(2427.19 \mu \mathrm{g} / \mathrm{ml})$. Compressive strength showed an average (MPa) for day1 (93.84 \pm 8.30$)$; day14 (67.83 \pm 4.82$)$ and day $21(51.08 \pm 2.10)$ respectively. Data from the compressive strength was analyzed by ANOVA, and it proved a significant decrease as the water immersion duration increases $(\mathrm{p}<0.05)$.

Conclusions: The duration of water immersion of e-glass FRC showed different effect on the concentration of released monomer and the compressive strength. Highest concentration of MMA concentration happened on day14 and followed by a decrease. As for the compressive strength, it decreased as the water immersion duration increased.

\section{Introduction}

The loss of tooth can happen due to caries or periodontal diseases. This condition might cause functional disabilities that needs the construction of a prosthesis. One common prosthesis is the crown or bridge, specifically the porcelain-fused-to-metal (PFM) model. It has the advantage which is relatively natural looking with good mechanical properties. Unfortunetely, the porcelain used in the prosthesis construction is relatively brittle, it has the tendency to crack and fracture easily (Hobkirk et al., 2003). Other disadvantage is the possibility of corrotion in the metallic part that might happen (Freilich et al., 2000). 
To overcome such problems, a new material has been developed. Fiber-reinforced composite (FRC) has provided the dentists the possibility of fabricating crown or bridge with esthetically good and metal-free tooth restorations for teeth replacement (Garoushi et al., 2011). Nowadays FRC is gaining its popularity (Schutt et al., 2004), as the use of this material might support the concept of minimal invasive dentistry. Fiber-reinforced composite has the modification of dental resin composite using either glass or carbon fibers (Mc Cabe and Walls, 2007). This material has fine thin fibers as reinforcement which gives good tensile strength and flexural modulus (Mallick, 2007). The superiority of FRC compared to resin composite is its good strength (Van Noort, 2007). Fiber-reinforced composite has at least two distinct constituents, the reinforcing component which gives good strength and stiffness, while the surrounding matrix supports reinforcement (Freilich et al., 2000). It has been explained that glass fibers have high tensile strength, with good impact and compression properties which make it more desired reinforcing material (Le Bell-Ronnlof, 2012).

Fiber-reinforced composite has an interpenetrating polymer network (IPN) structure, whereas the matrix is consisted from a crosslinking polymer, a linear polymer and a photoinitiator to react the polymerization (Zhang and Matinlinna, 2011). The mechanical strength of FRC depends much on the impregnition of fibers within the resin matrix and adhesion of fibers to the matrix (Valittu, 1998; Valittu, 1999; Valittu,2002). One of the most commonly used resin matrix which forms a good crosslinking polymer structures is the bis-phenol-Adiglycidylmethacrylate (bis-GMA) (Zhang and Matinlinna, 2011). Methyl methacrylate as a linear polymer (Zhang and Matinlinna, 2011) is joined to form a crosslinking polymer (Anusavice, 2009). Camphoroquinon (CQ) and N-N-cyanoethyl methylaniline (CEMA) are the common used photosensitizer and reducing agents (Zhang and Matinlinna, 2011). The structure of bis-GMA is as figured below

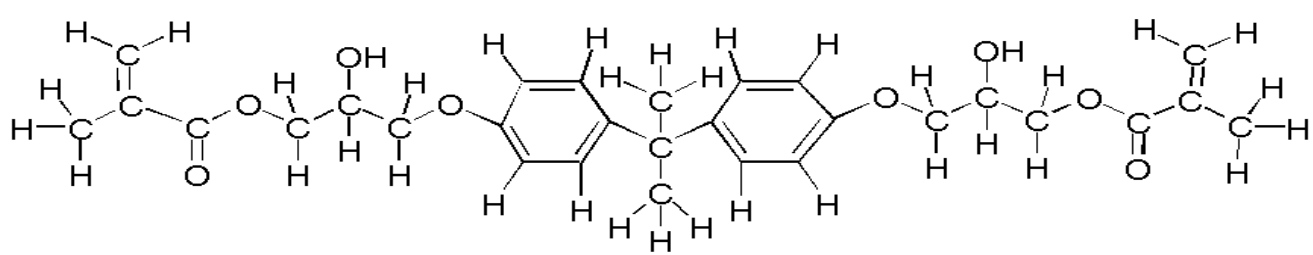

Figure 1. The structure of bis-phenol-A-glycidylmethacrylate (bis-GMA)

Dental composites are widely used in dentistry due to their esthetic and good in physical and mechanical properties (Tuan Rahim et al., 2012). The presence of water in saliva and other fluids of the mouth will give a very moist environment to the oral, which will cause the hydration of composite. The exposure of FRC to the oral environment causes detrimental effect of water sorption (Takashi et al., 2006). This condition will result in the swelling of the material due to the sorption of water into the resin matrix (Eliades et al., 2005). With time water molecules will act as plasticizers and decrease the mechanical properties (Mese and Guzel, 2008). It also will increase the materials solubility, and cause leakage of fillers which in turn breaks the bond between filler and matrix. A long term aging, for about 2 years of composites in water proved to significantly reduce the material fracture toughness (Drummond, 2008). It is investigested that water sorption of FRC specimens were in equilibrium from 4 days to 22 days (Zhang and Matinlinna, 2011). The immersion time for most composite resins, normally will saturate within 7-60 days (Tuan Rahim et al., 2012), while materials like acrylic resin may require only in a period of 17 days to become fully saturated with water (Anusavice, 2009).

Monomer system is the backbone of the dental composite (Garcia et al., 2005). Another issue 
of composite resin with oral environment is the release of unreacted monomers from the material (Sideridou et al., 2004). Water enters resin through porosities and intermolecular spaces. Monomers will leach out of material via pores and cracks in which the water enters the resin (Goldberg 2007). The release of components will implicate in the adverse reaction and damage the patiens health (Moharamzadeh et al., 2009). Some released monomers are known to ellicit cytotoxic effets (Sakaguchi and Powers, 2012), and methyl methacrylate is mentioned as cytotoxic (Pradeep and Sreekumar,2012).

The objective of this study was to measure the effect of water immersion duration on monomer release and the compressive strength of fiber-reinforced composite.

\section{Materials and Methods}

\subsection{Materials}

The materials used in the study are listed in table 1.

Table 1. Materials used in the study

\begin{tabular}{ll}
\hline Material & Manufacturer \\
\hline Bis-GMA & Sigma Aldrich, USA \\
Methylmethacrylate (MMA) & ProSciTech, Australia \\
Camphorquinone (CQ) & Esstech, USA \\
N,N-cyanoethyl methylaniline (CEMA) & Esstech, USA \\
Unidirectional E-glass fibers & Stick Tech Ltd, Turku, Finland \\
\hline
\end{tabular}

The E glass fibers (R338-2400/V/P) were already silanized by the manufacturer and kept in a desiccators for 24 hours prior to specimen preparation. The fibers were sized by immersion in a sizing solution for 1 minute. The sized fibers were cut into $25 \mathrm{~mm}$ long with a surgical steel knife (Matinlinna et al., 2009).

\subsection{Specimens preparation}

Specimens with the composition of $78.4 \%$ bis-GMA+19.6\%MMA+1.0\%CQ+1.0\%CEMA were prepared. Fifteen specimens $(2 \mathrm{~mm}$ x $2 \mathrm{~mm}$ x $25 \mathrm{~mm})$ were divided into 2 groups: compressive strength (1specimens) and residual monomer ( 3 specimens). Each specimen had two fiber rovings of $25 \mathrm{~mm}$ and placed in a mould, and light-cured with halogen light-curing unit on both sides for $3 x 40$ s. After light-curing, all specimens were polished using polishing paper of 360 grit (Matinlinna et al., 2009). The specimens were immersed in distilled water for 24 hours, $37^{\circ} \mathrm{C}$ before the testing. Specimens from each group were divided into three groups based on the water immersion durations (1,14 and 21days). The three residual monomer test specimens were analyzed using HPLC to test the concentrations. All compressive strength test specimens were tested using UTM (Torsee's UTM, Tokyo Testing Machine Mfg.,Co., Ltd.Japan) for the strength.

\subsection{Specimens testing}

\subsubsection{Monomer release}

Three specimens were labeled into three different time durations $(1,14$, and 21 days). Tubes were filled with $10 \mathrm{ml}$ distilled water. Each specimen was put in tube and stored in incubator at $37^{\circ} \mathrm{C}$. After each time duration was achieved, the extracting medium was analyzed using 
high performance liquid chromatography (HPLC - Shimadzu Class VP, Kyoto Japan) equipped with $\mathrm{C} 185 \mu \mathrm{m}, 250 \mathrm{~mm}$ legth, $4.5 \mathrm{~mm}$ diameter column, with an UV/DAD detector, using mobile phase of $\mathrm{CH}_{3} \mathrm{CN} / \mathrm{H}_{2} \mathrm{O}$ (7:3), at a flow rate of $1 \mathrm{~mL} / \mathrm{min}$ with $20 \mu \mathrm{L}$ injection at room temperature (Örtengren et al., 2001).

High performance liquid chromatography examination performed qualitative and quantitative data. First it performed the qualitative analysis by comparing the chromatogram of the studied specimens with the standards. As for the quantitative data, the peak-areas of the chromatograms gained from the released monomers were compared to a standard calibration curved, which was obtained by plotting the peak areas against known concentrations of the monomer standard. By referring the peak areas from the HPLC analysis of the specimens,to the standard calibration curve, the amount of each component was calculated in $\mu \mathrm{g} / \mathrm{ml}$ (Sofou et al, 2007).

\subsubsection{Compressive strength}

ThTwelve specimens were labelled into three different duration of immersion (day 1, 14, and 21). Each specimens was immersed in a tube with $10 \mathrm{ml}$ distilled water. All tubes were then placed in the incubator at $37^{\circ} \mathrm{C}$ throughout their immersion time. Once the immersion time is over, the spacemens were taken out and dried.

Each tested specimen was placed on the testing machine at a standing position directly below the crosshead of the Universal Teting Machine (Torsee's Universal Testing Machine, Tokyo Testing Machine Mfg. Co., Ltd., Tokyo Japan). Once the specimen was in place, the machine's crosshead was configured to move at $0.5 \mathrm{~mm}$ per minute speed at then the force used to break the specimen, as specified by the machine's dial gauge, noted in kilogram force.

To calculate the compressive strength of the specimens, the following formula was used to convert the force of compression in kilogram force to mega pascal. The formula is as follow (Klymus et al, 2007).

$$
\mathrm{C}(\mathrm{MPa})=\mathrm{F}(\mathrm{kgf}) \times 9.807 / \mathrm{A}
$$

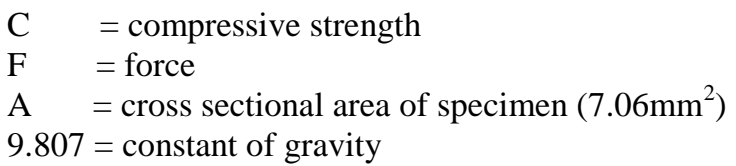

\subsection{Data analysis}

The concentration of monomers were analyzed using descritive method. As data obtained from the compressive strength test were analyzed by SPSS release 17.0 software. The level of statistical significant $\mathrm{p}$ was set as 0.05 . The data normality was examined by KolmogorovSmirnov test. One way analysis of variance (ANOVA) followed by Post hoc least significant different (LSD) test were carried out. The dependent variables (compressive strength) were compared with independent factor (water immersion duration).

\section{Results}

\subsection{Monomer release}

The concentrations of MMA released from e-glass fiber-reinforced composite was obtained by calculating the peak area of each specimen using formula $y=354.61 \mathrm{x}-18.459$ from the 
standard curve. The concentrations of MMA from each specimen obtained was in percentage and converted into $\mu \mathrm{g} / \mathrm{ml}$.

$\mathrm{y}=354.61 \mathrm{x}-18.459$

$\mathrm{x}=\mathrm{y}+18.459$

354.61

$\mathrm{y}=$ area $; \mathrm{x}=$ concentration of monomer $(\mu \mathrm{g} / \mathrm{ml})$

Table 2. The concentration of monomer release in different time durations

\begin{tabular}{|c|c|c|}
\hline Days & Sample area & Concentration $(\mu \mathrm{g} / \mathrm{ml})$ \\
\hline 1 & 64.9795 & 2352.96523 \\
\hline 14 & 108.0359 & 3567.15547 \\
\hline 21 & 91.0694 & 3088.70026 \\
\hline
\end{tabular}

As perform in table 2 the concentration of methyl methacrylate was increasing from day 1 to day 14 , but it decreased on day 21.

\subsection{Compressive strength}

The mean compressive strength of e-glass fiber-reinforced composite as seen in table 3 , was obtained after the calculation for water immersion durations of 1 day, 14 days and 21 days. This descriptively data shows a pattern that the compressive strength of FRC decreases as the duration of water imersion increases. The data was then analysed using the one-way ANOVA test with confidence level of $95 \%$, as presented in table 4 .

Table 3. Mean and standard deviation of compressive strength after water immersion

\begin{tabular}{|c|c|}
\hline $\begin{array}{c}\text { Duration of water } \\
\text { immersion (Days) }\end{array}$ & $\begin{array}{c}\text { Mean } \pm \text { standard } \\
\text { deviation }(\mathrm{MPa})\end{array}$ \\
\hline 1 & $93.84 \pm 8.31$ \\
\hline 14 & $67.83 \pm 4.82$ \\
\hline 21 & $51.08 \pm 2.10$ \\
\hline
\end{tabular}

Table 4. The one-way analysis of variance (ANOVA) of compressive strength after water immersion

\begin{tabular}{|c|c|c|c|c|c|}
\hline Source & Sum of squares & Degree of freedom & Mean square & F value & Significance \\
\hline Between & $\mathbf{3 8 8 4 . 7 9}$ & $\mathbf{2}$ & $\mathbf{1 9 4 2 . 3 9}$ & $\mathbf{5 4 . 2 0}$ & $\mathbf{0 . 0 1}$ \\
\hline $\begin{array}{c}\text { Groups } \\
\text { within }\end{array}$ & $\mathbf{3 2 2 . 5 3}$ & 9 & $\mathbf{3 5 . 8 4}$ & - & - \\
\hline $\begin{array}{c}\text { Groups } \\
\text { total }\end{array}$ & $\mathbf{4 2 0 7 . 3 1}$ & 11 & - & - & - \\
\hline
\end{tabular}

Result presented in table 4 proves that the probability, which is shown in the significance column, is 0.01 . This value is less than 0.05 , means that the time duration of water immersion of e-glass fiber-reinforced composite decreases the compressive strength is accepted. Least significant difference (LSD) post-hoc comparison test proves there is a significant difference between all grooups, as presented in table 5 . 
Table 5. Least Significance Difference (LSD) of compressive strength after water immersion

\begin{tabular}{|l|c|c|c|}
\hline Between Groups & Day 1 & Day 14 & Day 21 \\
\hline Day 1 & - & $28.06^{*}$ & $43.47^{*}$ \\
\hline Day 14 & & - & $15.40^{*}$ \\
\hline Day 21 & & & - \\
\hline
\end{tabular}

* significant

\section{Discussion}

Monomer is a chemical substance capable of reacting to form polyme (Anusavice, 2009). Monomer system is known as the backbone of dental composite (Garcia et al, 2005), and in water immersion the residual monomer may dissolve in water (Tanaka. 1991). Water enters the polymer through porosities and intermolecular spaces. Water diffuses into the network and separates the polymer chains and will create expansion. The expansion of polymer chain will cause the chain breaks and monomers will leach out (Goldberg 2007). Methyl methacrylate has smaller molecular weight than bis-GMA. It indicates that MMA will diffuse faster than bis-GMA. This is to clarify why the presence of MMA is found in all sample groups. The release of residual MMA from polymer appliances into saliva might cause redness, swelling and pain of the oral mucosa. In oral cavity, residual MMA might affect the surrounding tissues through some chemical reactions, such as oxidation and hydrolysis (Huang et al, 2000).

The amount of eluted monomers increases with time (Zhang and $\mathrm{Xu}, 2008$ ), and othher study investigated that water sorption of FRC were in equilibrium from day 4 to 22 (Zhang and Matinlinna, 2011). This study showed that the highest elution of MMA reached within the first 14 days and started to decrease on 21 days of water immersion. It can be explaned that on days 14 water immersion of e-glass FRC reached its equilibrium, the eluted monomers obtained is in the highest. It is possible that within 14 days, there are still remaining residual monomers of MMA eluted in distilled water, thereby after 14 days the concentration of MMA decreased

Fiber-reinforced composite is intended to be used in the oral cavity, and the oral environment is never be free from moisture. This condition is becoming a problem as the absorption of water might cause changes in mechanical properties, which will influence the effectivenes of the material. When FRC is exposed to moisture, it instantaneously absorb it into its surface (Mallick, 2007).

The e-glass fiber-reinforced composite continuosly absorbs water from the day it was immersed (Zhang and Matinlinna, 2011). This condition occurs due to the penetration of water molecules into the components FRC through active diffusion and cappilary flow via the crazes. Swelling of composite happens and this phenomenon causes the loss of mechanical properties of the material, as water acts as plasticizer and break the matrix-filler bond (Mese and Guzel, 2006). This can be a proof from the result presented in table 3, where the mean compressive strength of e-glass FRC descriptively shows a pattern that the compressive strength decreases as the duration of water immersion increases. 
The loss of the bond between matrix and filler of FRC, makes water able to enter the interpenetrating polymer network between the composite components and its fiber. Water molecules break the bond between polymer and fiber, which is formed by the silane coupling agents, by the leachig of glass forming oxides or alkaline oxides from the surface of the fiber and the hydrolytic degradation of the polysiloxane network from the hydrolysis and polycondensation of the coupling agent (Lassila et al., 2002).

Statistical analysis of the ANOVA as showed in table 4, exhibits that the duration of water immersion does indeed significantly reduce the compressive strength of e-glass fiberreinforced composite. Further analysis, the Least Significant Difference (LSD) as sperformed in table 5, showed there is a significant difference in compressive strength among the three groups. This result is related to the fact that there is an increase amount of water absorbed as time progresses. It is stated (Zhang and Matinlinna, 2011) that the absorption of water by eglass FRC increases constantly from the moment it was immersed till day 4, and after that the rate of water absorption will have a constant rate till day 22.

It is stated that a fixed prosthesis is supposed to be able to withstand at least $14 \mathrm{MPa}$ occlusal force when tested in a static position (Zhang and Matinlinna, 2011). Due to the result of this study that the mean compressive strength at its lowest which was $51.08 \mathrm{MPa}$ is higher than $42 \mathrm{MPa}$, this material fulfills the standard compressive strength of fixed prosthesis. .

\section{Conclusion}

The effect of water immersion on residual monomer and compressive strength of e-glass fiber-reinforced composite has been studied. It was proved that the duration of water immersion of e-glass FRC showed different effect on the concentration of released MMA and the compressive strength. Highest concentration of MMA happened on day 14 and followed by a decrease on day 22. As for the compressive strength, it decreased as the water immersion duration increased.

\section{References}

Anusavice KJ. Phillip's Science of Dental Materials, $11^{\text {th }}$ ed, Elsevier Science, St Louis, 2009, p.77.

Drummond JL. Degradation Fatigue and Failure of Resin Dental Composite Materials. J Dent Res 2008, 87: 3.

Eliades G., Watts DC., and Eliades T. Dental Hard Tissues and Bonding: Interfacial Phenomenon and Related Properties. Springer, Berlin. 2005, p 80-83.

Esstech. Material Safety Data Sheet. Product: 1,6-Hexanediol Dimethacrylate, code: X 887 7446, Esstech, USA, 2011, p 1-8.

Freilich MA., Meiers JC., Duncan JP., Goldberg AJ. Fiber-Reinforced Composites in Clinical Dentistry. Quintessence Publishing Co. Inc., Illinois. 2000,p 1-3. 
Garcia AH., Martinez Lozano MA., Vila JC., Escribano AB., Fos Galve P. Composite resins - A review of the materials and clinical idications. Med Oral Patol Oral Cir Bucal. 2006. 11: 215-220.

Garoushi S., Lassila L., Vallittu PK. Resin-Based Fiber-Reinforced Composite for Direct Replacement of missing Anterior Teeth: A Clinical Report. Int J of Dentistry. Vol 2011. Article ID 8455420.

Goldberg M. In vitro and in vivo studies on the toxicity of dental resin components: A review. Clin Oral Investig. 2008. no. 12. pp. 1-8

Hobkirk JA, Watson RM, Searson LJJ. Introducing Dental Implants. Churchill Livingstone, London, 2003, p. 22-25.

Huang FM., Hu CC., Chang YC., Chou MY. Residual monomer releasing from acrylic denture base in water. Chin Dent J. 19 (1).2000. pp. 17-22.

Klymus ME., Arai Shinkai RS., Mota EG., Silva Oshima HM., Spohr AM., Burnett Jr LH. Influence of the mechanical properties of composites for indirect dental restorations on pattern failure. Stomatologia Baltic Dental and Maxillofacial J. 2007 (9).pp. 58.

Lasilla LVJ., Hohrstrom T., Valittu PK. The influence of short term water storage on the flexural properties of unidirectional glass fiber-reinforced composites, Biomaterial. 23 (10). 2002. pp. 2221-2222.

Le Bell-Ronnlof AM. Fiber-reinforced Composites available at http://www.doria.fi/ bitstream/handle/10024/33576/D780.pdf?sequence=1,pg 22-24 on January 22, 2012.

Mallick PK., Fiber-Reinforced Composites: Materials, Manufacturing and Design, 3rd., CRC Press. Boca Roca, 2007. p 42-47.

Matinlinna JP., Dahl JE., Karlsson S., Lassila LV., Valittu PK. In Silanes and Other Coupling Agents. Vol 5. VSP/Brill, Leiden, The Netherlands, 2009. p. 107-121.

McCabe JF, Walls AWG. Applied Dental Materials. $9^{\text {th }}$ ed. Blackwell Munsgaard, Oxford, pp.213-215.6. Mallick PK. Fiber-reinforced composites : materials, manufacturing and design, $3^{\text {rd }}$ ed. CRC Press, Boca Raton, 2007, p. 42-58.

Mese A and Guzel KG., Effect of storage duration on the hardness and tensile bond strength of silicone- and acrylic resin-based resilient denture liners to a processed denture base acrylic resin. J Prosthet Dent. 2008. 99(2):153-9.

Moharamzadeh K., Brook IM., Van Noort R. Biocompatibility of Resin-based Dental Materials. Materials 2009, 2, 514-548; doi:10.3390/ma2020514.

Örtengren U., Wellendorf H., Karlsson S., Ruyter IE. Water sorption and solubility of dental composites and identification of monomer released in aquaous environment. J Oral Rehab. 28. 2001. pp. 1106-1115. 
Powers JM., Sakaguchi RL. Restorative Dental Materials. 12th ed. Evolve, Missouri, 2003, p 229.

Pradeep N and Sreekumar AV. An investigation into the cytotoxicity of methyl methacrylate monomer. 2012. J Contemp Dent Pract. Nov 1.13(6): 838-841.

Schutt A., Burki G., Schwaller P., Michler J., Cattani-Lorente M., Vallitu P., Bouillaguet S. Mechanical Properties of Fibre-reinforced dental Composites Subjected to Hydrothermal and Mechanical Ageing. Euro Cells and Mater. Vol. 7 - Suppl 2. 2004.

Sideridou I., Achilias DS., Spyroudi C., Karabela M. Water Sorption Characteristics of LightCured Dental Resins and Composites Based on Bis-EMA/PCDMA. Biomaterials. 2004. (25): 367-376.

Sofou, Afrodite, Tsoupi, Irene, Karayannis, Miltiades, Owall, Bengt. Determination of residual monomers released from soft lining materials with the use of HPLC. Pak J Anal Environ Chem. 2007. 8(2): pp. 41-52.

Takashi Y., Chai J., Tan SW. Effect of water storage on the impact strength of three glass fiber-reinforced composites. Dent Mat. 2006. 22: 291-297.

Tuan Rahmi TNA., Mohamad D., Akil HM., Abdul Rahman I. Water Sorption Characteristics of Restorative Dental Composites Immersed in Acidic Drinks. Dent Materials. 2012. (28): 63-70

Vallittu PK. The Effect of Glass Fiber Reinforcement on the Fracture Resistance of Provisional Fixed Partial Denture.J Prosthet Dent 1998;79:125 - 130.

Vallittu PK. Flexural Properties of Acrylic Resin Polymers Reinforced with Unidirectional and Woven Glass Fibers.J Prosthet Dent 1999;81:318 - 326.

Vallittu PK. Strength and Interfacial Adhesion of FRC-tooth System. In: Vallittu PK, editor. The Second International Symposium on Fibre-Reinforced Plastics in Dentistry. University of Turku, Institute of Dentistry and Biomaterials Research; 2002.

Van Noort R. Introduction to Dental Materials. 3rd Ed. Elsevier Health Sciences. London.p 120. 2007

Zhang M., and Matinlinna JP. The Effect of Resin Matrix Composition on Mechanical properties of E-glass Fibre-Reinforced Composite for Dental Use. $J$ of Adhesion Science and Tech. 2011. 19(25): 2687-2701, DOI: 10.1163/016942411x556051

Zhang M., and Matinlinna JP. E-Glass Fiber Reinforced Composites in Dental Applications. Silicon 2012: (4): 73-78. 